DOI: $10.17805 / z p u .2016 .4 .15$

\title{
Режимы публичности и приватности в социальных медиа
}

\author{
Е. С. ПРОНКИНА \\ (РОССИЙСКИЙ ГОСУДАРСТВЕННЫЙ ГУМАНИТАРНЫЙ УНИВЕРСИТЕТ)
}

Появление социальных медиа знаменует новый этап в дискуссиях о приватном и публичном. Цифровая среда диктует собственные условия организации социального пространства, создавая возможность для взаимного проникновения публичного и приватного, что ставит под вопрос релевантность подобного разделения. В свою очередь изучение перераспределения публичного и приватного в социальных медиа способствует пониманию пользовательских практик в сети. Одной из самых распространенных практик в социальных сетях является рассказ о своей личной жизни.

В статье предпринимается попытка сформулировать основания изучения таких практик, а также изучается особый кейс массового раскрытия интимных деталей собственной жизни, произведенного в рамках флешмоба "Я не боюсь сказать" (\#Янебоюсьсказать), который стартовал в июле 2016 г. в украинском сегменте социальной сети Facebook, а затем перешел и на российский сегмент. Данная массовая акция, посвященная проблеме сексуального насилия, привлекла внимание достаточно большого количества пользователей социальной сети Facebook, а также средств массовой информации. Нивелирование границы между общезначимыми событиями и личной жизнью отдельного человека вызвало неоднозначную реакцию пользователей сети и спровоцировало возникновение дискуссий о допустимости и недопустимости проговаривания интимных деталей личной жизни в публичном пространстве.

Данная акция позволяет зафиксировать сдвиги публичного и приватного в современном информационном пространстве, а также определить значение практики самораскрытия пользователей социальных сетей. Множество индивидуальных высказываний о личной жизни, объединенных общей идеей, заставляет переосмыслить разделение на видимое и невидимое, проговариваемое и умалчиваемое. В целом флешмоб вписывается в повседневную практику рассказа о личной жизни, но в то же время демонстрирует социокультурную значимость личного.

Ключевые слова: социальные медиа; социальные сети; Facebook; публичное; приватное; интимное; флешмоб

\section{BВЕАЕНИЕ}

$\mathrm{B}$ начале июля 2016 г. в украинском сегменте социальной сети Facebook стартовал флешмоб "Я не боюсь сказать" (с хэштегом \#Янебоюсьсказать ), направленный против сексуального насилия, который затем распространился и среди российской аудитории. В рамках этой акции пользователи делились собственными историями о насилии, совершенном над ними. Основная цель данного флешмоба - публично высказать то, что умалчивается, и указать на распространенность насилия в современном обществе. Однако реакция аудитории социальных медиа оказалась весьма неоднозначной. Одна часть пользователей приветствовала акцию и поддержала открытость его участников, другая - отнеслась скептически, осудила раскрытие интимных подробностей личной жизни или же увидела в ней феминистский проект, освещающий надуманную проблему.

Разбирая этот конкретный пример, можно попытаться понять множественные повседневные практики самораскрытия в социальных медиа. В рамках данной работы предлагается рассматривать публикацию личного контента как коммуникационную практику, влияющую на режимы приватности-публичности и организацию социального пространства. Существует несколько подходов к определению дихотомии «пуб- 
личное - приватное» и работе с этими понятиями. Наиболее часто публичная сфера описывается через практики рационально-критической дискуссии (Ярская-Смирнова, Романов, 2013: 7). Публичная сфера представляет собой область социальной коммуникации, обсуждения общезначимых вопросов, тогда как сфера приватного является оплотом личной жизни индивида.

\section{ЕАИНСТВО И БОРЬБА ПУБАИЧНОГО И ПРИВАТНОГО}

Обычно публичная и приватная сфера характеризуются через оппозицию друг другу (Habermas, 1991: 2). Аихотомия «публичное - приватное» преимущественно определяется либо через противопоставление видимого невидимому, либо - через противопоставление коллективного индивидуальному (Weintraub, 1997: 5). Более подходящим представляется выведение на первый план бинарной оппозиции «видимое - невидимое», так как оно соотносится с дискуссиями пользователей о том, что может быть проговорено в публичном пространстве, а что должно быть предметом умолчания.

Ю. Хабермас утверждал, что разрастание публичной сферы и видимое усиление публичности приводит к потере ее значения (Habermas, 1991: 4). Аействительно, когда все постепенно становится публичным, публичность перестает быть существенной. По Хабермасу, изменения не обходят стороной и сферу приватного, которая со временем также теряет свое значение, поскольку ряд функций приватной сферы забирают различные социальные институты (там же: 155-156). Развитие массмедиа приводит к тому, что активное участие в публичных дискуссиях и в собственной частной жизни сменяется потреблением медийной дискуссии (там же: 162; 170-172). Массмедиа захватывают социальное и интимное пространство индивида, создавая видимость публичности и приватности, но в действительности размывая границы между этими сферами и замещая их общей медийной реальностью. Становление Интернета и возникновение социальных медиа по-новому актуализируют эти рассуждения. С одной стороны, социальные медиа создают условия для развития публичных дискуссий, с другой стороны - способствуют большему размытию границы между публичностью и приватностью.

Р. Сеннет также отмечает закат публичного и важную роль медиа в этом процессе, хотя и расставляет акценты несколько иначе. Он утверждает, что приватность теряет свою связь с публичностью, замыкаясь в самой себе; существование в ней становится самоцелью индивида (Сеннет, 2002: 9). На первый план выходят чувства, намерения, раскрытие самости. В этой ситуации интерес к интимному превалирует над интересом к другим областям жизни человека. Ааже социальное оценивается через эту призму. Как полагает Сеннет, электронные СМИ усиливают ориентацию на интимно-личностный опыт и уводят прочь от социальных взаимодействий (там же: 321). Сегодня социальные медиа создают условия для формирования социальных взаимодействий. В то же время они производят новые возможности для раскрытия самости и выражения личных мыслей и чувств, что, в конечном счете, делает практики выражения себя более интенсивными.

Так, дискуссии о трансформации публичного и приватного выходят на новый виток. Утверждается ли подъем публичного пространства или же его иллюзорность, постулируется исчезновение приватности или же засилье приватного контента, вытесняющего другие типы высказываний, - все это образует дискурс, отмечающий сдвиги в отношениях публичного и приватного. Тем не менее цифровая среда диктует более гибкие подходы к пониманию этих отношений. Среди них можно выделить подход, 
рассматривающий публичное и приватное как тесно связанные области, конституирующие друг друга. Так, Н. Юргенсон и П. Аж. Рей полагают, что в цифровой среде публичное и приватное усиливают друг друга, то есть происходит одновременное приращение и приватности, и публичности (Jurgenson, Rey, 2013: 62). Они утверждают, что пользовательские практики в сети необходимо рассматривать как перфоманс, опирающийся как на видимое, так и на невидимое (там же: 64-66). Так, в социальных сетях пользователи нуждаются в защите собственной приватности, чтобы они могли активно продолжать помещать информацию о себе в публичное пространство (там же: 68).

Исследователь социальных медиа А. Бойд также поддерживает эту логику неоднозначности противостояния публичного и приватного. Она указывает на тот факт, что наша приватность априори носит сетевой характер и раскрытие какой-то информации может обнажить приватное пространство сразу нескольких людейп (Воу , 2012: Электронный ресурс). В условиях социальных медиа вероятность подобного раскрытия увеличивается, а потому регулирование собственного приватного пространства посредством ограничения доступа к определенной информации оказывается несостоятельным. Альтернативной моделью защиты приватного пространства представляется контроль над значениями публикуемой информации (там же). Так, например, можно сообщить о собственном отношении к чему-либо совершенно разными способами: выложить аудиозапись, нарисовать шарж или же просто написать сообщение, содержание которого может понять только узкий круг людей. Регулирование значения позволяет формировать разные типы аудиторий и публик, существующих в различных контекстах и по-разному интерпретирующих то или иное сообщение (Ваут, Boyd, 2012: Электронный ресурс). Таким образом пользователь сам определяет свое социальное пространство и устанавливает свой порядок коммуникации.

\section{РАСКРЫВАЯ ИНТИМНОЕ}

Одним из интимных аспектов жизни человека, обычно скрываемых от взгляда постороннего наблюдателя, является область сексуальности. В цикле работ, посвященных истории сексуальности, М. Фуко поднимает тему говорения о сексуальности и ее замалчивания, осмысляя сексуальность как дискурс. Согласно взглядам Фуко, сексуальность имеет глубинную связь с властью, которая действует через принуждение к воспроизводству говорения о сексе, то есть выведение секса в дискурс (Фуко, 1996: 108). Ж. Бодрийяр переосмыслил говорение о сексуальности через свою концепцию гиперреальности. В рамках этой концепции сексуальное становится не просто видимым, его репрезентации заполняют собой все социокультурное пространство, становясь более реальными, чем сам секс, в результате чего секс исчезает в гиперреальности (Бодрийяр, 2007: Электронный ресурс). Таким образом, и умолчание, и говорение связаны с установлением определенного дискурсивного режима. В то же время выведение в пространство видимого оказывается процессом изменения значения репрезентации.

Большой вклад в осмысление значения интимной сферы внесли гендерные исследования. В рамках этого подхода личная жизнь осмысляется в контексте политического, а феминистская деятельность рассматривается как направленная на деконструкцию оппозиции публичное-приватное (Скиба, 2010: Электронный ресурс). Флешмоб \#Янебоюсьсказать полностью вписывается в эту парадигму, так как он фактически стирает границу, разделяющую интимную жизнь людей и социально значимые события. 
Однако несмотря на указание массового характера проблемы насилия, опубликованные в рамках флешмоба истории являются прежде всего высказываниями об интимном. Неприятие у определенной части аудитории вызывает именно присваивание публичного статуса данным высказываниям. В свою очередь подобные высказывания становятся значимыми именно благодаря раскрытию интимности в публичном дискурсе. Значит, участвуя в этих дискуссиях, пользователям приходится существовать и в пространстве публичного, и в пространстве приватного одновременно.

Публикуя свою историю, автор раскрывает то, что было скрыто, рассказывая какую-то тайну о самом себе. Аж. Батлер в работе «Отдавая отчет о себе» пишет, что самоописание рождает проблему невозможности рассказа о своем раскрытии (Батлер, 2008: 108). Рассказ разворачивается в пространстве определенного дискурса, и дискурс частично присваивает его. То есть даже «самое-самое» личное в момент раскрытия перестает быть таковым. Из-за того, что описание себя обращено к кому-то, его автору приходится отказаться от этого описания в тот момент, когда он определяет его как свое (там же: 109). В случае с флешмобом подобная ситуация становится более наглядной. Сама его суть подразумевает диалогичность высказывания. Высказывания его участников мгновенно присваиваются, интерпретируются, вписываются в разнообразные контексты и становятся частью противоборствующих дискурсов. В соответствие с постмодернистским пафосом индивидуальное высказывание предстает частью всеобщего письма (Барт, 1989: 384-391).

Однако следует помнить, что в основе этих историй лежат личные, предельно интимные переживания. Интерпретируя известный феминистский лозунг «личное это политическое» (Hanisch: Электронный ресурс), мы можем глубже понять значение публикуемых историй. Эти истории запрашивают то же внимание, что обычно уделяют общественно значимым проблемам, а общий хэштег \#Янебоюсьсказать указывает на то, что эти истории представляют собой нечто большее и придают высказываниям дополнительную символическую ценность. Множество голосов, повторяющих «Я не боюсь сказать» и обращающихся к анонимной аудитории, утверждают политическую, социальную, культурную значимость личного.

\section{ЗАКАЮЧЕНИЕ}

Общий девиз акции «Я не боюсь сказать» как бы намекает на то, что раскрытие подобных деталей своей жизни выходит за рамки каких-то дискурсивных конвенций. Множество высказываний апеллирует к молчанию, делая его видимым, заставляя пользователей социальной сети осмыслить сам факт существования молчания. Каждое отдельное высказывание, выступающее под этим девизом, отстаивает таким образом определенную политику высказывания. Эта политика строится на том, чтобы пользователь мог сам регулировать пространство, в котором существует высказывание. В обществе, в котором присутствуют запреты на некоторые высказывания, подкрепленные негласными правилами приличия или законодательством, например, на высказывания о равноценности разных типов сексуальности (см.: Федеральный закон ..., 2013: Электронный ресурс), требование права видимости, права голоса через выражение личного представляет собой один из способов борьбы за свою социальную позицию. Из-за того, что высказывание пользователя существует одновременно в нескольких измерениях, автор может сам регулировать режимы его видимости, делая его более публичным или более приватным, более личным или же более политическим. 
Аелая такие высказывания, говорящий выступает одновременно с нескольких позиций: публичного и приватного. Поэтому закономерным будет предположение, что и воспринимать, и реагировать на подобное высказывание также следует и с позиции публичного, и с позиции приватного, так как вытеснение любого из этих режимов существования высказывания оказывается насилием по отношению к нему. Оппозиция «публичное - приватное» как система координат, позволяющая человеку ориентироваться в социальном мире (Эльштайн, 2000: 65-66), утрачивает свое прежнее значение. Вероятно, социальные медиа запрашивают новые основания для ориентации в социальном пространстве, продиктованные способностью существования в смешанных режимах приватного и публичного, личного и политического, индивидуального и коллективного.

\section{СПИСОК АИТЕРАТУРЫ}

Федеральный закон от 29 июня 2013 г. № 135-Ф3 г. Москва «О внесении изменений в статью 5 Федерального закона "О защите детей от информации, причиняющей вред их здоровью и развитию" и отдельные законодательные акты Российской Федерации в целях защиты детей от информации, пропагандирующей отрицание традиционных семейных ценностей» (2013) [Электронный ресурс] // Российская газета. 2 июля. URL: http://www.rg.ru/2013/06/30/deti-sitedok.html (дата обращения: 23.09.2016).

Барт, Р. (1989) Избранные работы: Семиотика. Поэтика / пер. с фр. М. : Прогресс. 616 с.

Батлер, Аж. (2008) Отдавая отчет о себе // Гендерные исследования. № 17. С. 104-120.

Бодрийяр, Ж. (2007) Забыть Фуко. [Электронный ресурс]// Antropology. Web-кафедра философской антропологии. URL: http://anthropology.ru/ru/text/bodriyar-zh/zabyt-fuko (дата обращения 24.11.2015).

Сеннет, Р. (2002) Падение публичного человека / пер. с англ. М. : Аогос. 424 с.

Скиба, Э. (2010) Теоретические дискуссии между феминизмом конца ХХ века и гендерной теорией [Электронный ресурс] // Науково-теоретичний і громадсько-політичний альманах «Грані». № 2. URL: http://www.nbuv.gov.ua/old_jrn/Soc_Gum/Grani/2010_2/F-10.pdf (дата обращения: 23.09.2016).

Фуко, М. (1996) Воля к истине: по ту сторону власти, знания и сексуальности. Работы разных лет / пер. с фр. М. : Касталь. 448 с.

Эльштайн, Аж. Б. (2000) Императивы приватного и публичного // Хрестоматия феминистских текстов. Переводы / под ред. Е. Здравомысловой, А. Темкиной. СПб. : ИзА-во «Амитрий Буланин». 303 с. С. 64-88.

Ярская-Смирнова, Е. Р., Романов, П. В. (2013) Публичная сфера: программа исследования // Публичная сфера: теория, методология, кейс стади / под ред. Е. Р. Ярской-Смирновой, П. В. Романовой. М. : Центр социальной политики и гендерных исследований. 360 с. С. 7-22.

Baym, N. K., Boyd, D. (2012) Socially Mediated Publicness: An Introduction. [Электронный реcypc] // Taylor \& Francis Online. URL: http://www.tandfonline.com/doi/full/10.1080/08838151. 2012.705200 (дата обращения 22.09.2016).

Boyd, D. (2012) Networked privacy [Электронный ресурс]// Surveillance and Society. Vol. 10. № 3/4. URL: http://ojs.library.queensu.ca/index.php/surveillance-and-society/article/view/networked (дата обращения: 22.09.2016).

Jurgenson, N., Rey, P. J. (2013) The fan dance: how privacy thrives in the age of hyper publicity // Unlike Us Reader. Social media monopolies and their alternatives / ed. by G. Lovink, M. Rasch. Amsterdam : Institute of Network Cultures. 384 p. P. 61-75.

Habermas, J. (1991) The Structural Transformation of the Public Sphere. An Inquiry into a Category of Bourgeois Society : transl. by Germ. Cambridge : The Mit Press, Massachusetts. 301 p.

Hanisch, C. The personal is political [Электронный ресурс]// University of Roehampton. URL: http://www.roehampton.ac.uk/uploadedFiles/Pages_Assets/PDFs_and_Word_Docs/Courses/Dram a_Theatre_and_Performance/PersonalisPol[1].pdf (дата обращения: 23.09.2016). 
Weintraub, J. (1997) The Theory and Politics of the Public / Private Distinction // Public and Private in Thought and Practice: Perspectives on a Grand Dichotomy / ed. by J. Weintraub, K. Kumar. Chicago : University of Chicago Press. 399 p. P. 1-42.

Аата поступления: 25.09.2016 г.

\section{PUBLIC AND PRIVATE MODES IN SOCIAL MEDIA}

\section{E. S. PRONKINA}

(RUSSIAN STATE UNIVERSITY FOR THE HUMANITIES)

The rise of the social media indicates a new stage in the discussions of the private and public. The digital environment imposes its own terms on the organization of the social space, which leads to intermingling of the public and private, thus defying the very relevance of this binary opposition. In its turn, the study of how the public and private are redistributed on social media helps understand practices adopted by users of social networks. One of the most common practices is telling the story of one's personal life.

This paper outlines the scientific foundations of practices of the public and private on social media, with a special focus on the case study of mass revelation of intimate details as part of the flashmob "I am not afraid to say" (\#Yaneboyusskazat'). The flashmob began in July 2016 in the Ukrainian segment of Facebook, also spreading across its Russian segment. The flashmob posts covered the problem of sexual violence and soon caught the eye of many Facebook users, as well as mass media. Tearing down the border between the events of general significance and the private life of an individual was met with mixed reaction from Facebook users and provoked debates on whether it is admissible to talk about intimate details of private life in a public space.

This collective action indicated a shift in the understanding of public and private in contemporary information space, allowing us to assess the meaning of self-revealing practices employed by social media users. Many individual statements about personal life united by a common idea contribute to the rethinking of the oppositions between the visible and the invisible, the articulated and the concealed. In general, the flashmob \#Yaneboyusskazat fits into the everyday practice of telling a personal story, at the same time demonstrating the sociocultural significance of the individual.

Keywords: social media; social networks; Facebook; public; private; intimate; flashmob

\section{REFERENCES}

Federal'nyi zakon ot 29 iiunia 2013 g. N 135-FZ g. Moskva "O vnesenii izmenenii v stat'iu 5 Federal'nogo zakona "O zashchite detei ot informatsii, prichiniaiushchei vred ikh zdorov'iu i razvitiiu" i otdel'nye zakonodatel'nye akty Rossiiskoi Federatsii v tseliakh zashchity detei ot informatsii, propagandiruiushchei otritsanie traditsionnykh semeinykh tsennostei" (2013). Rossiiskaia gazeta, 2 July [online] Available at: http://www.rg.ru/2013/06/30/deti-site-dok.html (access date: 23.09.2016). (In Russ.)

Barthes, R. (1989) Izbrannye raboty: Semiotika. Poetika. Moscow, Progress. 616 p. (In Russ.)

Butler, J. (2008) Otdavaia otchet o sebe. Gendernye issledovaniia, no. 17, pp. 104-120. (In Russ.)

Baudrillard, J. (2007) Zabyt' Fuko. Antropology. Web-kafedra filosofskoi antropologii [online] Available at: http://anthropology.ru/ru/text/bodriyar-zh/zabyt-fuko (access date: 24.11.2015). (In Russ.)

Sennet, R. (2002) Padenie publichnogo cheloveka. Moscow, Logos. 424 p. (In Russ.)

Skiba, E. (2010) Teoreticheskie diskussii mezhdu feminizmom kontsa XX veka i gendernoi teoriei. Naukovo-teoretichnii i gromads'ko-politichnii al' manakb "Grani", no. 2 [online] Available at: http:// www.nbuv.gov.ua/old_jrn/Soc_Gum/Grani/2010_2/F-10.pdf (access date: 23.09.2016). (In Russ.).

Foucauld, M. (1996) Volia $\bar{k}$ istine: po tu storonu vlasti, znaniia i seksual' nosti. Raboty raznykb let. Moscow, Kastal'. 448 p. (In Russ.)

Elshtain, J. B. (2000) Imperativy privatnogo i publichnogo. In: Khrestomatiia feministskikb tekstov. Perevody, ed. E. Zdravomyslova and A. Temkina. St. Petersburg, Dmitrii Bulanin Publ. 303 p. Pp. 64-88. (In Russ.) 
Iarskaia-Smirnova, E. R. and Romanov, P. V. (2013) Publichnaia sfera: programma issledovaniia. In: Publichnaia sfera: teoriia, metodologiia, keis stadi, ed. E. R. Iarskoi-Smirnova and P. V. Romanova. Moscow, Tsentr sotsial'noi politiki i gendernykh issledovanii. 360 p. Pp. 7-22. (In Russ.)

Baym, N. K. and Boyd, D. (2012) Socially Mediated Publicness: An Introduction. Taylor \& Francis Online [online] Available at: http://www.tandfonline.com/doi/full/10.1080/08838151.2012.705200 (access date: 22.09.2016).

Boyd, D. (2012) Networked privacy. Surveillance and Society, vol. 10. № 3/4 [online] Available at: http://ojs.library.queensu.ca/index.php/surveillance-and-society/article/view/networked (access date: 22.09 .2016$)$.

Jurgenson, N. and Rey, P. J. (2013) The fan dance: how privacy thrives in the age of hyper publicity. In: Unlike Us Reader. Social media monopolies and their alternatives, ed. by G. Lovink and M. Rasch. Amsterdam, Institute of Network Cultures. 384 p. Pp. 61-75.

Habermas, J. (1991) The Structural Transformation of the Public Sphere. An Inquiry into a Category of Bourgeois Society. Cambridge, The Mit Press, Massachusetts. 301 p.

Hanisch, C. The personal is political. University of Roebampton [online] Available at: http:// www.roehampton.ac.uk/uploadedFiles/Pages_Assets/PDFs_and_Word_Docs/Courses/Drama_The atre_and_Performance/PersonalisPol[1].pdf (access date: 23.09 .2016$)$.

Weintraub, J. (1997) The Theory and Politics of the Public / Private Distinction. In: Public and Private in Thought and Practice: Perspectives on a Grand Dichotomy, ed. by J. Weintraub and K. Kumar. Chicago, University of Chicago Press. 399 p. P. 1-42.

Submission date: 25.09.2016.

Пронкина Елена Сергеевна - аспирант кафедры истории и теории культуры Российского государственного гуманитарного университета. Адрес: 125993, Россия, Москва, Миусская пл., А. 6, корп. 5. Тел.: +7 91541928 09, +7 495 250-68-27. Эл. адрес: pronkina-elena1307@yandex.ru. Научный руководитель: А-р истор. наук, проф. Г. И. Зверева.

Pronkina Elena Sergeevna, Postgraduate student, Department of History and Theory of Culture, Russian State University for the Humanities. Postal address: 6 Bldg. 5 Miusskaia Square, 125993 Moscow, Russian Federation. Tel.: +7 91541928 09, +7 495 250-68-27. Email: pronkina-elena1307@yandex.ru. Research advisor: Doctor of History, Professor G. I. Zvereva. 